\title{
Mental distress and its associations with behavioral outcomes during the COVID-19 pandemic: A national survey of Chinese adults
}

\author{
Lu Ma ( $\square$ maluhappy14@163.com ) \\ Xi'an Jiaotong University \\ Liwang Gao \\ Xi'an Jiaotong University \\ Joseph Tak-fai Lau \\ Chinese University of Hong Kong \\ Rahman Atif \\ University of Liverpool \\ Blair T. Johnson \\ University of Connecticut \\ Alice Fang Yan \\ Medical College of Wisconsin \\ Zumin Shi \\ Qatar University \\ Yixin Ding \\ Xi'an Jiaotong University \\ Peng Nie \\ Xi'an Jiaotong University \\ Jinge Zheng \\ Xi'an Jiaotong University \\ Youfa Wang \\ Xi'an Jiaotong University \\ Weidong Wang \\ Renmin University of China \\ Qian-Li Xue \\ Johns Hopkins University
}

Research

Keywords: COVID-19, Mental distress, Socio-demographic and disease factors, Change in behavioral outcomes, Adults, China

Posted Date: August 12th, 2020

DOI: https://doi.org/10.21203/rs.3.rs-56290/v1

License: () (1) This work is licensed under a Creative Commons Attribution 4.0 International License. Read Full License

Version of Record: A version of this preprint was published at Public Health on September 1st, 2021. See the published version at https://doi.org/10.1016/j.puhe.2021.07.034. 


\section{Abstract}

Background This study primarily aimed to evaluate the associations between mental distress and COVID-19-related changes in behavioral outcomes, and potential modifiers (age, gender, and educational attainment) of such associations.

Methods An online survey using anonymous network sampling was conducted in China during April-May, 2020 using a 74-item questionnaire distributed through social media. A national sample of 10,545 adults in 31 provinces provided data on socio-demographic characteristics, COVID-19-related mental distress, and changes in behavioral outcomes. Structural equation models were used for data analyses.

Results About $13 \%$ of adults reported experiencing at least one symptom of mental distress. After adjusting for covariates, greater mental distress was associated with increased smoking and alcohol consumption (among current smokers and drinkers) and with both increased and decreased physical activity. Underweight adults were more likely to lose body weight ( $\geq 1 \mathrm{~kg}$ ) whereas overweight adults were more likely to gain weight by the same amount. Association between mental distress and change in physical activity was stronger in adults aged 40 and above and those with high education.

Conclusions Mental distress was associated with increased smoking in males but not females. These findings inform the design of tailored public health interventions aimed to mitigate long-term negative consequences of mental distress on outcomes.

\section{Background}

Globally, the COVID - 19 pandemic has led to elevated levels of mental distress (e.g., anxiety and depression) attributed to prolonged lockdowns, business closures, and social isolation $(1,2)$. It is assumed that relaxing lockdown restrictions might reduce mental distress in China as the economy and social connections begin to normalize (1) even while the global impact of the pandemic continues to escalate. It is important to investigate the magnitude and associations of mental distress at various time-points during the COVID-19 pandemic. Studies from China during the initial COVID-19 outbreak showed that socio-demographic factors (e.g., marital status and female gender) $(3,4)$ and preexisting health status (e.g., presence of chronic diseases) (1) were associated with increased mental distress in adults, while associations with age were found to be mixed $(5,6)$. Socio-economic adversity (e.g., increasing unemployment and financial insecurity) was associated with increased mental distress in adults (7).

Associations of mental distress with behavioral outcomes and body weight during the pandemic is less explored. Psychological theories have suggested that mental distress can result in adaptive coping that include health promotion behaviors and/or maladaptive coping that involves health compromising behaviors (8). There is ample empirical evidence existed prior to the COVID-19 pandemic. For example, systematic reviews showed that experiencing anxiety and depression was associated with weight gain $(9,10)$. Mental distress also changed lifestyles such as heavy drinking, smoking, and less physical activity (PA) in adults (11). Limited such studies however have been conducted during the COVID-19 pandemic (12). It is conceivable that lockdowns and social distancing measures for controlling COVID-19 spread necessarily entail modifying people's behavioral patterns (13). Therefore, it is contented that mental distress may be associated with body weight and behavioral outcomes during the COVID-19 pandemic.

To fill these knowledge gaps at this important time during the COVID-19 pandemic, this national cross-sectional study aims to: (a) examine the magnitude and predictors of mental distress; (b) investigate the impacts of mental distress on change in behavioral outcomes (PA, smoking, and alcohol consumption) and body weight; and whether such impacts were modified by age, gender, and education attainment among Chinese adults.

\section{Methods}

\section{Study design and participants}

The China COVID-19 survey was an anonymous online study administered from April 25- May 11, 2020 via WeChat, China's leading social networking with more than one billion users. Almost every Chinese adult uses WeChat daily. We used both snowball and convenience sampling to recruit a diverse national sample across China. Data were obtained from 10,545 adults aged 18-80 years old in all 31 province-level administrative units in mainland China. The Institutional Review Board at Xi'an Jiaotong University Health Science Center approved study procedures, and participants provided consent online. An incentive of 1-10 RMB was provided after completing the survey.

\section{Study variables and measurements}

The China COVID-19 survey questionnaire included 74 questions.

Mental distress was assessed with a 5-item scale to assess the respondent's mental distress experienced during the COVID-19 pandemic. As we wanted to evaluate symptoms related to COVID-19 stress, we adapted items from the widely used and validated DSM-IV based civilian version of the posttraumatic stress disorder checklist (PCL-C) (14). The scale asks about symptoms in relation to "stressful experiences" and can be used with any population. It measures the intensity of symptoms encountered in the past month: (a) Anhedonia: loss of interest in activities you liked in the past; (b) Sleep problems: difficulty falling asleep, or staying asleep, or waking up frequently or early; (c) Anger: got easily irritable or angry; (d) Difficulty concentrating, and (e) Repeated disturbing dreams related to COVID-19. Response options for each question include a five-point scale from "not at all" to "extremely". We choose these items based on our pilot study in more than 400 adults in China, which showed that these mental distress symptoms were most frequently reported in adults during the pandemic. 
Changes in behavioral outcomes: Changes in PA, smoking, and alcohol consumption were measured by self-reported individual items extracted from Kadoorie Study of Chronic Disease in China (15) and from the China Chronic Disease and Risk Factor Survey (16) developed by the China Center for Disease Control Chronic Disease Control Center. The items, adapted for COVID-19, include: (a) Changes in PA measured by "Has your usual weekly PA changed compare to that before the COVID-19 pandemic?" (b) Change in smoking was measured by "Has your smoking pattern changed compared to that before the COVID-19 pandemic?" (c) Changes in alcohol consumption was measured by "Whether your alcohol consumption has changed compare to that before the COVID-19 pandemic?" Each response used a 5-point Likert scale which ranged from "Increased a lot" $=1$ to "Reduced a lot" =5; Data analyses on changes in smoking and alcohol consumption were limited to those who were current smokers $(n=1,633)$ and alcohol drinkers $(n=2,354)$ at the time of the survey.

Change in body weight: Participants' self-reported weight changes (current weight compared to weight prior to the COVID-19 outbreak) were measured. Responses included, "No change (change within 1 kg)" =1, "Increased 1-2.5 kg" =2, "Increased>2.5kg" =3, “Decreased 1-2.5 kg" =4, "Decreased>2.5 kg" =5, and "I don't know" =99.

Other study variables: Associations of socio-demographic and pandemic-related factors with mental distress were examined, and socio-demographic factors were included as covariates in the models for investigating the independent associations of mental distress with behavioral outcomes and body weight. Socio-demographic factors included age, gender, marital status (unmarried, married, cohabiting, widowed, divorced or separated), ethnicity (Han and Not-Han), educational attainment ( $\leq$ primary school, secondary school/technical secondary school/technical school, undergraduate/graduate school), current work status (students, have job, jobless, and retirement), residence (urban, town, rural), health insurance (yes, no), and presence of any chronic diseases (e.g., hypertension and diabetes, total number of having chronic diseases were calculated).

Factors related to COVID-19 pandemic included impact on family income (great impact, slight impact, and no impact), impact on daily life due to financial difficulties during the COVID-19 pandemic (great difficulty, slight difficulty, and no difficulty), and loss of job due to COVID-19 (yes, no). All these items were based on a questionnaire developed by Conway and colleagues and used in previous surveys (17). Worry of contracting COVID-19 (not worried at all, a little worried, somewhat worried, and very worried) and perceptions about the likely of contracting COVID-19 (not at all likely, not that likely, somewhat likely, and very likely) were measured with respective single item adapted from a recent COVID-19 awareness, attitude, and action questionnaire (18).

\section{Statistical analysis}

First, descriptive analysis was conducted. Then, percentage differences in socio-demographic and pandemic-related factors by mental distress quartile were tested. For descriptive purpose, the quartiles were formed based on the summed score of the five items. $\chi^{2}$ test and ANOVAs were used to compare categorical and continuous variables, respectively.

For inferential analyses, we first evaluated the dimensionality and internal construct validity of mental distress scale using exploratory factor analysis in the overall sample. To account for the ordinal scale of the item responses, poly choric correlations were used in model fitting by treating the ordinal scale for each item as a discretized continuous latent response scale via a probit link. Based on principal components analysis in conjunction with Horn's parallel analysis (19), one common factor was found to be sufficient for explaining the co variation among the five indicators of mental distress. This one-factor model accounted for $81 \%$ of the total variation, with a Cronbach's alpha of 0.87 (Root Mean Square Error of Approximation (RMSEA)=0.124, $90 \%$ confidence interval = 0.117 - 0.131; Comparative Fit Index $(\mathrm{CFI})=0.995 ;$ Tucker-Lewis Index $(\mathrm{TLI})=0.989)$.

To identify predictors that were associated with mental distress, we fit a structural equation models (SEM) with mental distress factor as the dependent latent variable with covariates including age, sex, marital status, ethnicity, education, health insurance, residence, current work status, household size, body mass index, self-reported health, number of chronic conditions, COVID's impact on family income, daily life, and job loss, and worries about self or family getting infected. The model was fit using a weighted least square minimum variance estimator.

We fit a SEM that consisted of a factor measurement model for mental distress and a multinomial logistic structural model for associations between mental distress during COVID-19 pandemic and changes in the behavioral outcome and body weight. Age, gender, ethnicity, marital status, educations, residence, and number of chronic conditions were adjusted in all models.

To explore the potential modification of the relationships between mental distress and behavioral changes by pre-COVID-19 factors including age, gender, and educational attainment, multiple-group SEMs were conducted under the assumptions of measurement invariance and structural variance. Separate models were fit for each outcome variable with and without constraining the path coefficient between mental distress and the outcome to be same between levels of the effect modifier. The effect modification was tested using the Satorra-Bentler scaled $\chi^{2}$ difference test (20). The SEMs were fit using maximum likelihood with robust standard errors in Mplus version 8.

Analyses were performed by using STATA 16.1 (Stata Corporation, College Station, TX, U.S.), except Mplus version 8.0 was used for SEM. Statistical significance was considered when $\mathrm{p}<0 \cdot 05$.

\section{Results}


Figure 1 shows the distribution of symptoms of mental distress of participants. About 13\% of them reported experienced "a lot" or "extreme" anhedonia, and a similar proportion reported sleep problems, repeated disturbing dreams or irritability, and anger in the past month. About 15\% had "a lot" to "extreme"

difficulties in concentrating.

\section{Socio-demographic and COVID-19 related factors associated with mental distress}

The SEM with all covariates in the models revealed that those with higher levels of mental distress tendered to be male, of younger age, cohabiting, absence of health insurance, either having a job or jobless, having a household size of $>5$ people, underweight, self-reported poor health, having chronic diseases, having family income impacted by COVID-19, experiencing at least mild difficulty with the family's daily life due to COVID-19-related financial strain, being somewhat or very worried about contracting COVID-19, and perceiving self or family somewhat or very likely to contracting COVID-19. In contrast, educational attainment, ethnicity, and residence were not associated with mental distress (Table 1).

\section{Adjusted associations between mental distress and changes in behavioral outcomes and body weight during the COVID-19 pandemic}

Figure 2 shows the distribution of changes in PA, smoking, alcohol consumption and body weight by quartiles of mental distress summary score. Across the quartiles of the mental health score from low to high, the proportion of stable body weight decreased.

In order to account for the effect of baseline weight status on the associations between mental distress and changes in body weight, we stratified our population by weight status (i.e., underweight, normal weight, and overweight/obesity). Age, gender, marital status, educational attainment, residence, and total number of chronic diseases were adjusted in all models. We found that among underweight participants, the odds of reporting an increase or decrease in body weight by at least $1 \mathrm{~kg}$ versus no change was, respectively, $40 \%$ and $63 \%$ higher per one standard deviation (SD) increase in mental distress; among overweight or obese participants, the odds of reporting an increase or decrease of body weight by at least $1 \mathrm{~kg}$ versus no change was, respectively, $61 \%$ and $48 \%$ higher per one SD increase in mental distress; and among participants with normal weight, the odds of reporting an increase or decrease of body weight by at least $1 \mathrm{~kg}$ versus no change was, respectively, $52 \%$ and $62 \%$ higher per one SD increase in mental distress (Table 2).

After adjusting for the same covariates, we found that among current smokers $(n=1,633)$ and alcohol drinkers $(n=2,354)$, greater mental distress was associated with significant increase ("some" or "a lot") in smoking [odds ratio (OR)=1·42, 95\% Cl: 1·20-1.68 and OR=1·54, 95\% Cl: 1·31-1·82 per one SD increase in mental distress]. Similar increase was seen in alcohol consumption (OR=1·67, 95\% Cl: 1·45-1.92 and OR=1·47, 95\% Cl: 1·24-1·75 per one SD increase in mental distress) (Table 2).

Greater mental distress was significantly associated with both increase and decrease in PA after adjusting for the same covariates (ORs ranged from 1.32 to $1 \cdot 56, p<0 \cdot 001)$ (Table 2).

\section{Potential modifying effects of age, gender, and educational attainment on associations between mental distress and behavioral outcomes}

Educational attainment significantly moderated the association between mental distress and change in PA. In general, the odds of PA increase "some" or "a lot", or "decrease a little" among adults with undergraduate/graduate school (OR=1·77, 95\% Cl: 1·58, 1·98; OR=1·64, 95\% Cl: 1·49, 1·79; OR=1·43, 95\% Cl: 1·30, $1 \cdot 56$, respectively, per one SD increase in mental distress) were higher than those education attainment less than undergraduate/graduate school (OR=1.36, 95\% Cl: 1·22, 1·51; OR=1·57, 95\% Cl: 1·42, 1·73; OR=1·25, 95\% Cl: 1·12, 1·39, respectively, per one SD increase in mental distress) (Supplemental Table 1).

Age significantly moderated the association between mental distress and change in PA. In general, the odds of PA "increase a little" or decrease "a little" or "a lot" (OR=2·05, 95\% Cl: $1 \cdot 72,2 \cdot 46$; OR=1·54, 95\% Cl: $1 \cdot 31,1 \cdot 81 ; \mathrm{OR}=1 \cdot 93,95 \% \mathrm{Cl}: 1 \cdot 62,2 \cdot 29$, respectively, per one SD increase in mental distress) among adults aged $\geq 40$ years were higher than among those adults aged $30-39$ years $(\mathrm{OR}=1 \cdot 50,95 \% \mathrm{Cl}: 1 \cdot 34,1 \cdot 67 ; \mathrm{OR}=1 \cdot 16,95 \% \mathrm{Cl}: 1 \cdot 03,1 \cdot 30 ; \mathrm{OR}=1 \cdot 61,95 \% \mathrm{Cl}: 1 \cdot 41,1 \cdot 84$, respectively, per one SD increase in mental distress) or 18-29 years old (OR=1·51, 95\% Cl: 1·38, 1·65; OR=1·40, 95\% Cl: 1·27, 1·55; OR=1·38, 95\% Cl: 1·24, 1·54, respectively, per one SD increase in mental distress) (Supplemental Table 2).

Gender significantly moderated the association between mental distress and change in smoking. Among current smokers, the odds of smoking increase "some" or "a lot" were significant among male (OR=1·60, 95\% Cl: 1·37, 1·87 per one SD increase in mental distress) not among female (OR=1·11, 95\% Cl: 0·82, $1 \cdot 51$ per one SD increase in mental distress) (Supplemental Table 3).

\section{Discussion}

To our knowledge, this is the first large nationwide survey in China on adults' mental distress related to COVID-19 pandemic and its impact on changes in behavioral outcomes and body weight. The study provides an opportunity to explore patterns of associations between mental distress and changes in healthrelated behaviors within the COVID-19 context, and highlights the issues that are likely to confront the public health systems in China and globally.

About $13 \%$ of participants reported experiencing at least one symptom of mental distress in the past month (March-April 2020). Studies conducted earlier in the pandemic showed greater mental distress and problems $(21,22)$. For example, a study conducted on 1,738 adults from 190 Chinese cities in January 31 to February 2 reported that $28.8 \%$ and $16.5 \%$ reported moderate-to-severe anxiety and depression at the initial outbreak, and no significant changes in these symptoms at four weeks later $(3,22)$. However, direct comparisons of the prevalence of mental distress across studies at different time-points of the pandemic are difficult due to the different measurement scales used. Many factors may contribute to the change in mental distress over time, such as controlling the spread of COVID-19, establishing confidence in public health measures, and supporting of material strategies (21, 23, 24). 
We found that economic impacts and risk for contracting COVID-19 negatively affected mental health in our population. A reduction in family income or financial strains due to COVID-19 were associated with greater mental distress. The links between mental health and poverty are well known. The potential fallout of an economic downturn on mental health is likely to be profound. It will be vital to understand the mental health implications of policies to manage the pandemic in the short-term, and the challenges of reviving the economy in the longer term, all of which would inevitably have serious effects on mental health by increasing unemployment, loss of job, and poverty (2). Worry about being infected and perception of self or family members being infected by the COVID-19 were associated with greater mental distress. These findings indicate that effective and rapid communication about the COVID-19 information is essential, as is ensuring that vital general and medical supplies are available to maintain a sense of security in the population (25).

Greater mental distress was associated with both increase and decrease in PA. While long-standing distress is known to be associated with chronic physical conditions, impact of acute distress on behaviors is less well known. It could lead to positive behaviors, for example, a survey in the UK ( $n=344)$ found that negative emotions, especially anxiety in response to the COVID-19 pandemic predicted adaptive health-compliant behavior change (e.g., hand washing) (26). A 2014 systematic review with 55 studies also showed that the majority of studies reported negative associations between mental distress and PA while some studies reported positive associations (27). These findings indicate that individuals' response to mental distress due to COVID-19 may vary by one's baseline attitudes to PA (27). In some individuals, engaging in PA could be a task-oriented way of dealing with mental distress. PA may serve to both deal with and steer away from mental distress. In this study, for adults with higher mental distress, $57.5 \%$ of them reported increased "a lot" or "a little", $26.2 \%$ of them reported decreased "a lot" or "a little". Additional strategies to promote PA among adults reduced their PA are needed.

However, our study indicates that some distressed people had chosen unhealthy coping behaviors. We found that among current smokers and alcohol drinkers, mental distress was associated with increase in smoking and alcohol consumption. This might also indicate that individuals with mental distress might increase these behaviors to cope with or relieve psychological distress during the pandemic (28). Our findings indicate that people adopt both adaptive and maladaptive behaviors to cope with mental distress during COVID-19 pandemic. Thus, one-size-fit-all public health strategies may not be the answer to the array of behaviors adopted to relieve mental distress and associated behaviors, and a more tailored approach might be warranted.

Age and educational attainment moderated associations between mental distress and change in PA. Our findings indicate that during this pandemic, the associations between mental distress and increase in PA was stronger among adults with more education and among adults aged $\geq 40$ years. Among current smokers, increase in mental distress resulted in increasing "some" or "a lot" in smoking were found only among male not female. Future policy makers and researchers should consider these pre-COVID-19 effect modifiers to maximize the effects of psychological intervention on behavioral outcomes. For example, psychological interventions could be effective to reduce smoking among male by improving their mental distress.

This study has several public health implications. On 13th May, 2020, the United Nation's Director General stated: "The mental health and wellbeing of whole societies have been severely impacted by this crisis and are a priority to be addressed urgently." (29). This study shows that acute distress of significant severity persisted in about $13 \%$ of the population as the immediate effects of the lockdown began to ease. However, significant mental distress symptoms in over 1 in 10 and more were alarmingly. Mental distress is likely to be exacerbated when economic hardships, joblessness, and disparities set in. Moreover, our findings suggest variability in the associations of mental distress with adaptive and maladaptive coping behaviors. Those who are already vulnerable, e.g., smokers and alcohol consumers were more likely to adopt maladaptive coping behaviors. Until a vaccine is found, access to face-to-face psychological care is likely to be very limited. Effective ways must be found to provide both psychological and behavioral interventions so chronic conditions can be avoided. Digital technology holds promise for improving access to, and quality of mental health care (30).

The present study has limitations. First, this survey is cross-sectional, making causal inferences difficult at best. Considering the mental health status may change during the pandemic, dynamic observation is necessary. Second, mental distress was based on self-administered questionnaires. Moreover, the items were extracted from PCL-C, not the full scale, this may lead to underestimate of the prevalence of mental distress. Nevertheless, mental distress is personal feelings, and self-reporting was paramount and convenient during the COVID-19 pandemic (1). Third, we could not rule out the possibility that some of the respondents might have been infected with COVID-19. Mental distress and behavioral outcomes of participants infected with COVID-19 may be different from those who were not being infected. Fourth, we did not do a sensitivity analyses to see if the results may be different in some provinces, such as Hubei where the pandemic started. Future studies may further explore.

The study has a number of strengths such as its collection of comprehensive information from a large national sample. Such anonymous surveys can better gauge people's honest answers, especially in questions about sensitive information. Moreover, they are more feasible in such special situation like COVID-19 than using traditional interpersonal methods.

\section{Conclusions}

Economic impacts and risk for contracting COVID-19 negatively impact mental distress of adults, and greater mental distress was associated with some positive and negative changes in behavioral outcomes during the pandemic. Our findings can inform the design of tailored public health interventions to mitigate negative consequences of COVID-19 and mental distress.

\section{List Of Abbreviations}

physical activity (PA); Root Mean Square Error of Approximation (RMSEA)

Comparative Fit Index (CFI); Tucker-Lewis Index (TLI); structural equation models (SEM)

standard deviation (SD); odds ratio (OR); 


\section{Declarations}

Ethics approval and consent to participate: Approval was obtained from the ethics committee of The Institutional Review Board at Xi'an Jiaotong University Health Science Center. The procedures used in this study adhere to the tenets of the Declaration of Helsinki. And informed consent was obtained from all individual participants included in the study.

Consent for publication: The participants had consented to the submission of the original article to the journal.

Availability of data and materials: The datasets used and/or analysed during the current study are available from the corresponding author on reasonable request.

Competing interests: The authors declare that they have no competing interests.

Funding: The project is supported in part by research grants from the China Medical Board (Grant number: 16-262), the University Alliance of the Silk Road (Grant number: 2020LMZX002), and Xi'an Jiaotong University Global Health Institute.

Authors' contributions: WDW, QLX, LM, YFW, AFY, and ZMS contributed to the study design, data collection, and drafting the manuscript. QLX, LWG, and ZMS contributed to the data analysis. LM and QLX drafted the manuscript. YFW directed the data collection and provided administrative support for the project. All authors contributed to interpretation of the data, commented on and revised the report, and approved the final version for publication.

\section{Acknowledgements}

We thank the study participants and collaborators and staff members who have contributed to the study. We thank Guorui Ruan, Lihua Yan, Bingtong Zhao, and Baibing Mi for their special assistance supporting this project.

\section{References}

1. Tan W, Hao F, McIntyre RS, et al. Is returning to work during the COVID-19 pandemic stressful? A study on immediate mental health status and psychoneuroimmunity prevention measures of Chinese workforce. Brain Behav Immun. 2020.

2. Holmes EA, O'Connor RC, Perry VH, et al. Multidisciplinary research priorities for the COVID-19 pandemic: a call for action for mental health science. Lancet Psychiatry. 2020.

3. Wang C, Pan R, Wan X, et al. Immediate Psychological Responses and Associated Factors during the Initial Stage of the 2019 Coronavirus Disease (COVID-19) Epidemic among the General Population in China. Int J Environ Res Public Health. 2020;17:5.

4. Lai J, Ma S, Wang Y, et al. Factors Associated With Mental Health Outcomes Among Health Care Workers Exposed to Coronavirus Disease 2019. JAMA Netw Open. 2020;3:3.

5. Özdin S, Bayrak Özdin Ş. Levels and predictors of anxiety, depression and health anxiety during COVID-19 pandemic in Turkish society: The importance of gender. Int J Soc Psychiatry. 2020:20764020927051.

6. Huo MK, Yin Y, Jiang LZ, Duan XY. Survey of mental health status of residents in Wuhan, Huanggang, Kunming and Yuxi in the early stage of COVID-19 epidemic. International Journal of Psychiatry. 2020;47:02.

7. Barr B, Taylor-Robinson D, Scott-Samuel A, McKee M, Stuckler D. Suicides associated with the 2008-10 economic recession in England: time trend analysis. Bmj. 2012;345.

8. Stanisławski K. The Coping Circumplex Model: An Integrative Model of the Structure of Coping With Stress. Front Psychol. 2019;10:694.

9. Geiker NRW, Astrup A, Hjorth MF, Sjödin A, Pijls L, Markus CR. Does stress influence sleep patterns, food intake, weight gain, abdominal obesity and weight loss interventions and vice versa? Obes Rev. 2018;19:1.

10. Mannan M, Mamun A, Doi S, Clavarino A. Prospective Associations between Depression and Obesity for Adolescent Males and Females- A Systematic Review and Meta-Analysis of Longitudinal Studies. PLoS One. 2016;11:6.

11. Hoang D, Kristoffersen I, Li IW. All in the mind? Estimating the effect of mental health on health behaviours. Soc Sci Med. $2019 ; 225$.

12. Stanton R, To QG, Khalesi S, et al. Depression, Anxiety and Stress during COVID-19: Associations with Changes in Physical Activity, Sleep, Tobacco and Alcohol Use in Australian Adults. Int J Environ Res Public Health. 2020;17:11.

13. Galea S, Merchant RM, Lurie N. The Mental Health Consequences of COVID-19 and Physical Distancing: The Need for Prevention and Early Intervention. JAMA Intern Med. 2020.

14. Reichenheim ME, Oliveira AG, Moraes CL, Coutinho ES, Figueira I, Lobato G. Reappraising the dimensional structure of the PTSD Checklist: lessons from the DSM-IV-based PCL-C. Braz J Psychiatry. 2018;40:2.

15. Chen Z, Lee L, Chen J, et al. Cohort Profile: The Kadoorie Study of Chronic Disease in China (KSCDC). Int J Epidemiol. 2005;34:6.

16. Yao Y, Liu G, Wang L, et al. Disease and disparity in China: a view from stroke and MI disease. InternationalJournal for Equity in Health. $2019 ; 18: 1$.

17. Conway LG, Woodard Shailee R, Zubrod A Social Psychological Measurements of COVID-19: Coronavirus Perceived Threat, Government Response, Impacts, and Experiences Questionnaires: National Institute of Health; 2020 [Available from: https://www.nlm.nih.gov/dr2/Scales_from_Social_Psychological_Measurements_of_COVID-19.pdf.

18. Wolf MS, Serper M, Opsasnick L, et al. Awareness, Attitudes, and Actions Related to COVID-19 Among Adults With Chronic Conditions at the Onset of the U.S. Outbreak. Annals of Internal Medicine. 2020. 
19. Horn JL. A RATIONALE AND TEST FOR THE NUMBER. OF FACTORS IN FACTOR ANALYSIS. Psychometrika. 1965;30.

20. Satorra A, Bentler PM. Ensuring Positiveness of the Scaled Difference Chi-square Test Statistic. Psychometrika. 2010;75:2.

21. Qiu J, Shen B, Zhao M. A nationwide survey of psychological distress among Chinese people in the COVID-19 epidemic: implications and policy recommendations. Gen Psychiatr. 2020;33:2.

22. Wang C, Pan R, Wan X, et al. A longitudinal study on the mental health of general population during the COVID-19 epidemic in China. Brain Behav Immun. 2020.

23. Makwana N. Disaster and its impact on mental health: A narrative review. J Family Med Prim Care. 2019;8:10.

24. Leon GR. Overview of the psychosocial impact of disasters. Prehosp Disaster Med. 2004;19:1.

25. Brooks SK, Webster RK, Smith LE, et al. The psychological impact of quarantine and how to reduce it: rapid review of the evidence. Lancet. 2020;395:10227.

26. Harper CA, Satchell LP, Fido D, Latzman RD. Functional Fear Predicts Public Health Compliance in the COVID-19 Pandemic. Int J Ment Health Addict. 2020.

27. Stults-Kolehmainen MA, Sinha R. The effects of stress on physical activity and exercise. Sports Med. 2014;44:1.

28. McLachlan KJJ, Gale CR. The effects of psychological distress and its interaction with socioeconomic position on risk of developing four chronic diseases. J Psychosom Res. 2018;109.

29. Nations U. Policy Brief: COVID-19 and the Need for Action on Mental Health 2020, 5.

30. Naslund JA, Aschbrenner KA, Araya R, et al. Digital technology for treating and preventing mental disorders in low-income and middle-income countries: a narrative review of the literature. Lancet Psychiatry. 2017;4:6.

\section{Tables}

Table 1. Study sample characteristics in all and by mental distress status of Chinese adults attending the 2020 China COVID-19 survey(n=10,545) 


\begin{tabular}{|c|c|c|c|c|c|c|c|c|c|c|}
\hline \multirow[t]{2}{*}{ Variables } & \multirow{2}{*}{$\begin{array}{l}\mathrm{N}(\%) \text { or } \\
\text { Mean } \pm \mathrm{SD}\end{array}$} & \multicolumn{5}{|c|}{ Mental distress quartile } & \multicolumn{4}{|c|}{ Mental distress total score (as a latent de } \\
\hline & & 1 & 2 & 3 & 4 & $p^{a}$ & Estimate & SE & Estimate/SE & $95^{\prime}$ \\
\hline (Low mental distress) & $\begin{array}{l}\text { (High } \\
\text { mental } \\
\text { distress) }\end{array}$ & & & & & & & & & \\
\hline All & & $2223(21 \cdot 1)$ & $2935(27 \cdot 9)$ & $2614(24 \cdot 8)$ & $2773(26 \cdot 2)$ & & & & & \\
\hline Gender & & & & & & $<0.001$ & & & & \\
\hline Male & $4605(43 \cdot 7)$ & $968(43 \cdot 5)$ & $1131(38 \cdot 5)$ & $1092(41 \cdot 8)$ & $1414(51 \cdot 0)$ & & Reference & & & \\
\hline Female & $5940(56 \cdot 3)$ & $1255(56 \cdot 5)$ & $1804(61 \cdot 5)$ & $1522(58 \cdot 2)$ & $1359(49 \cdot 0)$ & & $-0 \cdot 05$ & 0.02 & $-2 \cdot 43$ & $-0 \cdot($ \\
\hline Age (years) & $31 \cdot 8 \pm 9 \cdot 9$ & $32 \cdot 7 \pm 10 \cdot 3$ & $33 \cdot 2 \pm 10 \cdot 6$ & $31 \cdot 8 \pm 9 \cdot 9$ & $29 \cdot 5 \pm 8 \cdot 5$ & $<0.001$ & -0.01 & 0.00 & $-8 \cdot 74$ & $-0 \cdot($ \\
\hline Marital status & & & & & & $<0.001$ & & & & \\
\hline Unmarried & $3427(32 \cdot 5)$ & $646(29 \cdot 1)$ & $910(31 \cdot 0)$ & $850(32 \cdot 5)$ & $1021(36 \cdot 8)$ & & Reference & & & \\
\hline Married & $6545(62 \cdot 1)$ & $1495(67 \cdot 3)$ & $1905(64 \cdot 9)$ & $1641(62 \cdot 8)$ & $1504(54 \cdot 2)$ & & -0.07 & 0.03 & $-2 \cdot 49$ & -0 \\
\hline Cohabiting & $365(3 \cdot 5)$ & $36(1 \cdot 6)$ & $64(2 \cdot 2)$ & $70(2 \cdot 7)$ & $195(7 \cdot 0)$ & & $0 \cdot 17$ & 0.06 & $3 \cdot 04$ & 0.0 \\
\hline Widowed & $64(0 \cdot 6)$ & $12(0 \cdot 5)$ & $17(0 \cdot 6)$ & $11(0 \cdot 4)$ & $24(0 \cdot 9)$ & & 0.02 & $0 \cdot 13$ & $0 \cdot 16$ & $-0 \div$ \\
\hline Divorced or separated & $144(1 \cdot 3)$ & $34(1 \cdot 5)$ & $39(1 \cdot 3)$ & $42(1 \cdot 6)$ & $29(1 \cdot 1)$ & & $-0 \cdot 15$ & 0.09 & $-1 \cdot 76$ & $-0 \div$ \\
\hline Ethnicity & & & & & & 0.006 & & & & \\
\hline Han & $9942(94 \cdot 3)$ & $2108(94 \cdot 8)$ & $2782(94 \cdot 8)$ & $2477(94 \cdot 8)$ & $2575(92 \cdot 9)$ & & Reference & & & \\
\hline Not-Han & $581(5 \cdot 5)$ & $113(5 \cdot 1)$ & $144(4 \cdot 9)$ & $131(5 \cdot 0)$ & 193(7·0) & & 0.01 & 0.04 & 0.29 & $-0 \cdot($ \\
\hline Foreigner & $22(0 \cdot 2)$ & $2(0 \cdot 1)$ & $9(0 \cdot 3)$ & $6(0 \cdot 2)$ & $5(0 \cdot 2)$ & & 0.02 & $0 \cdot 18$ & $0 \cdot 10$ & $-0 \therefore$ \\
\hline Educational attainment & & & & & & $<0.001$ & & & & \\
\hline$\leq$ Primary school & $191(1 \cdot 8)$ & $46(2 \cdot 1)$ & $29(1 \cdot 0)$ & $33(1 \cdot 3)$ & $83(3 \cdot 0)$ & & Reference & & & \\
\hline $\begin{array}{l}\text { Secondary } \\
\text { school/Technical } \\
\text { secondary } \\
\text { school/Technical school }\end{array}$ & $3985(37 \cdot 8)$ & $835(37 \cdot 6)$ & $979(33.4)$ & $970(37 \cdot 1)$ & $1201(43 \cdot 3)$ & & $-0 \cdot 07$ & 0.07 & $-1 \cdot 01$ & $-0 \therefore$ \\
\hline $\begin{array}{l}\text { Undergraduate/Graduate } \\
\text { school }\end{array}$ & $6369(60 \cdot 4)$ & $1342(60 \cdot 3)$ & $1927(65 \cdot 6)$ & $1611(61 \cdot 6)$ & $1489(53 \cdot 7)$ & & $-0 \cdot 12$ & 0.07 & $-1 \cdot 66$ & $-0 \div$ \\
\hline $\begin{array}{l}\text { Health insurance (yes, } \\
\%)\end{array}$ & & & & & & $<0.001$ & & & & \\
\hline Yes & $9238(87 \cdot 6)$ & 1977(88.9) & $2655(90 \cdot 5)$ & $2285(87.4)$ & $2321(83 \cdot 7)$ & & Reference & & & \\
\hline No & $1307(12 \cdot 4)$ & $246(11 \cdot 1)$ & $280(9 \cdot 5)$ & $329(12 \cdot 6)$ & $452(16 \cdot 3)$ & & $0 \cdot 117$ & 0.033 & 3.53 & $0 \cdot 0$ \\
\hline Residence & & & & & & $0 \cdot 015$ & & & & \\
\hline City & $6493(61 \cdot 6)$ & $1414(63 \cdot 6)$ & $1825(62 \cdot 2)$ & $1576(60 \cdot 3)$ & $1678(60 \cdot 5)$ & & Reference & & & \\
\hline Town & $2470(23.4)$ & $505(22 \cdot 7)$ & $682(23 \cdot 2)$ & $653(25 \cdot 0)$ & $630(22 \cdot 7)$ & & 0.01 & 0.02 & 0.38 & $-0 \cdot($ \\
\hline Village & $1582(15 \cdot 0)$ & $304(13 \cdot 7)$ & $428(14 \cdot 6)$ & $385(14 \cdot 7)$ & $435(16 \cdot 8)$ & & -0.05 & 0.03 & $-1 \cdot 68$ & -0 \\
\hline Current work status & & & & & & $<0.001$ & & & & \\
\hline Students & $2075(19 \cdot 7)$ & $400(18)$ & $590(20 \cdot 1)$ & $498(19 \cdot 1)$ & $587(21 \cdot 2)$ & & Reference & & & \\
\hline Have job & $7015(66 \cdot 5)$ & $1554(69 \cdot 9)$ & $1970(67 \cdot 1)$ & $1727(66 \cdot 1)$ & $1764(63 \cdot 6)$ & & $0 \cdot 15$ & 0.03 & $4 \cdot 83$ & 0.0 \\
\hline Jobless & $1135(10 \cdot 8)$ & 199(9) & $256(8 \cdot 7)$ & $320(12 \cdot 2)$ & $360(13 \cdot 0)$ & & $0 \cdot 16$ & 0.04 & 3.94 & 0.0 \\
\hline Retirement & $320(3 \cdot 0)$ & $70(3 \cdot 1)$ & $119(4 \cdot 1)$ & $69(2 \cdot 6)$ & $62(2 \cdot 2)$ & & 0.08 & 0.07 & $1 \cdot 17$ & $-0 \cdot($ \\
\hline Household size (Total nun & ber) & & & & & $<0.001$ & & & & \\
\hline 1 & $92(0 \cdot 9)$ & $27(1 \cdot 2)$ & $22(0 \cdot 7)$ & $24(0 \cdot 9)$ & $19(0 \cdot 7)$ & & Reference & & & \\
\hline 2 & $684(6 \cdot 5)$ & $160(7 \cdot 2)$ & $187(6.4)$ & $163(6 \cdot 2)$ & $174(6 \cdot 3)$ & & $0 \cdot 14$ & $0 \cdot 11$ & $1 \cdot 30$ & $-0 \cdot($ \\
\hline 3 & $4383(41 \cdot 6)$ & $991(44 \cdot 6)$ & $1379(47)$ & $1036(39 \cdot 6)$ & $977(35 \cdot 2)$ & & $0 \cdot 15$ & $0 \cdot 11$ & 1.46 & $-0 \cdot($ \\
\hline 4 & $2680(25.4)$ & $557(25)$ & $713(24 \cdot 3)$ & $702(26 \cdot 9)$ & $708(25 \cdot 5)$ & & $0 \cdot 17$ & $0 \cdot 11$ & $1 \cdot 64$ & $-0 \cdot($ \\
\hline 5 & $1692(16 \cdot 0)$ & $308(13 \cdot 9)$ & $415(14 \cdot 1)$ & $420(16 \cdot 1)$ & $549(19 \cdot 8)$ & & $0 \cdot 21$ & $0 \cdot 11$ & $2 \cdot 02$ & 0.0 \\
\hline
\end{tabular}




\begin{tabular}{|c|c|c|c|c|c|c|c|c|c|c|}
\hline \multirow[t]{2}{*}{ Variables } & \multirow{2}{*}{$\begin{array}{l}\mathrm{N}(\%) \text { or } \\
\text { Mean } \pm S D\end{array}$} & \multicolumn{5}{|c|}{ Mental distress quartile } & \multicolumn{4}{|c|}{ Mental distress total score (as a latent de } \\
\hline & & 1 & 2 & 3 & 4 & $p^{a}$ & Estimate & SE & Estimate/SE & $95^{\prime}$ \\
\hline$\geq 6$ & $1014(9 \cdot 6)$ & $180(8 \cdot 1)$ & $219(7 \cdot 5)$ & $269(10 \cdot 3)$ & $346(12 \cdot 5)$ & & $0 \cdot 25$ & $0 \cdot 11$ & $2 \cdot 35$ & $0 \cdot 0$ \\
\hline \multicolumn{11}{|l|}{ Weight status } \\
\hline Normal weight & $6429(61 \cdot 0)$ & $1397(62 \cdot 8)$ & $1834(62 \cdot 5)$ & $1601(61 \cdot 3)$ & $1597(57 \cdot 6)$ & & Reference & & & \\
\hline Underweight & $1093(10 \cdot 3)$ & $200(9 \cdot 0)$ & $219(7 \cdot 5)$ & $290(11 \cdot 0)$ & $384(13 \cdot 9)$ & & $0 \cdot 11$ & 0.03 & 3.40 & 0.0 \\
\hline Overweight & $2108(20 \cdot 0)$ & $436(19 \cdot 6)$ & $642(21 \cdot 8)$ & $506(19.4)$ & $524(18 \cdot 9)$ & & -0.04 & $0 \cdot 02$ & -1.47 & $-0 \cdot 1$ \\
\hline Obesity & $915(8 \cdot 7)$ & $190(8 \cdot 6)$ & $240(8 \cdot 2)$ & $217(8 \cdot 3)$ & $268(9 \cdot 6)$ & & -0.07 & 0.04 & $-1 \cdot 88$ & -0 \\
\hline \multicolumn{6}{|c|}{ Impact on family income by COVID-19 } & $<0.001$ & & & & \\
\hline No impact & $1245(11 \cdot 8)$ & $484(21 \cdot 8)$ & $392(13.4)$ & $184(7 \cdot 0)$ & $185(6 \cdot 7)$ & & Reference & & & \\
\hline Great impact & $3997(37 \cdot 9)$ & $624(28 \cdot 1)$ & $883(30 \cdot 1)$ & $1058(40 \cdot 5)$ & $1432(51 \cdot 6)$ & & $0 \cdot 15$ & 0.04 & $3 \cdot 80$ & 0.0 \\
\hline Slight impact & $5303(50 \cdot 3)$ & $1115(50 \cdot 1)$ & $1660(56 \cdot 5)$ & $1372(52 \cdot 5)$ & $1156(41 \cdot 7)$ & & $0 \cdot 14$ & 0.03 & $4 \cdot 19$ & 0.0 \\
\hline \multicolumn{6}{|c|}{ Impact on daily life by financial difficulties during the COVID-19 pandemic } & $<0.001$ & & & & \\
\hline No difficulty & $3463(32 \cdot 8)$ & $749(33 \cdot 7)$ & $1281(43 \cdot 7)$ & $1399(53 \cdot 5)$ & $1273(45 \cdot 9)$ & & Reference & & & \\
\hline Great difficulty & $2380(22 \cdot 6)$ & $1090(49)$ & $1287(43 \cdot 8)$ & $669(25 \cdot 6)$ & $417(15)$ & & 0.56 & 0.04 & $16 \cdot 25$ & $0 \cdot 4$ \\
\hline Slight difficulty & $4702(44 \cdot 6)$ & $384(17 \cdot 3)$ & $367(12 \cdot 5)$ & $546(20 \cdot 9)$ & $1083(39 \cdot 1)$ & & $0 \cdot 35$ & 0.03 & $14 \cdot 34$ & $0 \cdot 3$ \\
\hline \multicolumn{6}{|c|}{ Loss of job because of COVID-19 } & $<0.001$ & & & & \\
\hline Yes & $3561(33 \cdot 8)$ & $520(23.4)$ & $751(25 \cdot 6)$ & $932(36 \cdot 7)$ & $1358(49 \cdot 0)$ & & Reference & & & \\
\hline No & $6984(66 \cdot 2)$ & $1703(76 \cdot 6)$ & $2184(74.4)$ & $1682(64 \cdot 3)$ & $1415(51 \cdot 0)$ & & $-0 \cdot 12$ & $0 \cdot 02$ & $-4 \cdot 93$ & $-0 \cdot$ \\
\hline \multicolumn{6}{|c|}{ Total number of chronic diseases ${ }^{c}$} & $<0.001$ & & & & \\
\hline 0 (no chronic disease) & $8431(80 \cdot 0)$ & $1953(87 \cdot 8)$ & $2528(86 \cdot 1)$ & 2118(81) & $1832(66 \cdot 1)$ & & Reference & & & \\
\hline 1 & $1024(9 \cdot 7)$ & $142(6.4)$ & $266(9 \cdot 1)$ & $272(10 \cdot 4)$ & $344(12 \cdot 4)$ & & $0 \cdot 23$ & 0.03 & $6 \cdot 66$ & $0 \cdot 1$ \\
\hline 2 & $591(5 \cdot 6)$ & $68(3 \cdot 1)$ & $79(2 \cdot 7)$ & $139(5 \cdot 3)$ & $305(11 \cdot 0)$ & & 0.46 & 0.05 & $10 \cdot 22$ & $0 \cdot 3$ \\
\hline$\geq 3$ & $499(4 \cdot 7)$ & $60(2 \cdot 7)$ & $62(2 \cdot 1)$ & $85(3 \cdot 3)$ & $292(10 \cdot 5)$ & & 0.55 & 0.05 & $12 \cdot 28$ & 0.4 \\
\hline \multicolumn{6}{|c|}{ How worried are you about being infected with COVID-19? } & $<0.001$ & & & & \\
\hline Not worried at all & $484(4 \cdot 6)$ & $211(9 \cdot 5)$ & $108(3 \cdot 7)$ & $54(2 \cdot 0)$ & $111(4 \cdot 0)$ & & Reference & & & \\
\hline A little worried & $2375(22 \cdot 5)$ & $603(27 \cdot 1)$ & $785(26 \cdot 8)$ & $515(19 \cdot 7)$ & $472(17 \cdot 0)$ & & 0.02 & 0.05 & $0 \cdot 49$ & $-0 \cdot($ \\
\hline Somewhat worried & $3608(34 \cdot 2)$ & $651(29 \cdot 3)$ & $1096(37 \cdot 3)$ & $974(37 \cdot 3)$ & $887(32 \cdot 0)$ & & $0 \cdot 13$ & 0.05 & $2 \cdot 66$ & $0 \cdot 0$ \\
\hline Very worried & $4078(38 \cdot 7)$ & $758(34 \cdot 1)$ & $946(32 \cdot 2)$ & 1071(41) & $1303(47 \cdot 0)$ & & $0 \cdot 17$ & 0.05 & 3.46 & $0 \cdot 0$ \\
\hline \multicolumn{6}{|c|}{ Do you think you or your family might be infected with COVID-19 this year } & $<0.001$ & & & & \\
\hline Not at all likely & $2024(19 \cdot 2)$ & $696(31 \cdot 3)$ & $517(17 \cdot 6)$ & $381(14 \cdot 6)$ & $430(15 \cdot 5)$ & & Reference & & & \\
\hline Very likely & $1237(11 \cdot 7)$ & $215(9 \cdot 7)$ & $182(6 \cdot 2)$ & $247(9.4)$ & $593(21.4)$ & & $0 \cdot 27$ & 0.04 & $7 \cdot 36$ & $0 \cdot 2$ \\
\hline Somewhat likely & $2573(24.4)$ & $380(17 \cdot 1)$ & $625(21 \cdot 3)$ & $743(28.4)$ & $825(29 \cdot 8)$ & & $0 \cdot 21$ & 0.03 & $7 \cdot 10$ & $0 \cdot 1$ \\
\hline Not that likely & $4711(44 \cdot 7)$ & $932(41 \cdot 9)$ & $1611(54 \cdot 9)$ & $1243(47 \cdot 6)$ & $925(33.4)$ & & 0.04 & 0.03 & $1 \cdot 50$ & $-0 \cdot 1$ \\
\hline \multicolumn{11}{|l|}{ Self-reported health } \\
\hline Excellent & $4211(39 \cdot 9)$ & $1371(61 \cdot 7)$ & $1055(36 \cdot 0)$ & $757(29 \cdot 0)$ & $1028(37 \cdot 1)$ & & Reference & & & \\
\hline Very good & $4235(40 \cdot 2)$ & $648(29 \cdot 1)$ & $1372(46 \cdot 8)$ & $1170(44 \cdot 8)$ & $1045(37 \cdot 7)$ & & $0 \cdot 32$ & 0.02 & $14 \cdot 68$ & $0 \cdot 2$ \\
\hline Good & $1790(17 \cdot 0)$ & $182(8 \cdot 2)$ & $473(16 \cdot 1)$ & $594(22 \cdot 7)$ & $541(19 \cdot 5)$ & & $0 \cdot 48$ & 0.03 & $17 \cdot 21$ & 0.4 \\
\hline Fair/poor & $309(2 \cdot 9)$ & $22(1 \cdot 0)$ & $35(1 \cdot 1)$ & $93(3 \cdot 6)$ & $159(5 \cdot 7)$ & & $0 \cdot 80$ & 0.05 & $15 \cdot 73$ & 0.7 \\
\hline
\end{tabular}

${ }^{a} \chi^{2}$ test for categorical variables.

${ }^{\mathrm{b}}$ Associations between socio-demographic and diseases factors and mental distress were examined using structural equation model, all the variables were in the same model. 
${ }^{\mathrm{C}}$ The chronic diseases measured in this survey included high blood pressure, diabetes, heart disease, stroke, tumor/cancer, asthma, chronic lung disease, chronic kidney disease, liver disease, compromised immune system, depression, and others.

Table 2. Adjusted* odds ratio (95\% confidence interval) of change (vs. no change) in body weight and behavioral outcomes of Chinese adults during COVID-19 pandemic associated with one standard deviation unit increase in mental distress

\begin{tabular}{|c|c|c|c|c|}
\hline Outcome & Baseline status & Response category & Total score of mental distress(per SD) & $\mathrm{P}$ \\
\hline \multirow{9}{*}{$\begin{array}{l}\text { Change in body weight } \\
(n=10,545)\end{array}$} & \multirow{3}{*}{$\begin{array}{l}\text { Underweight } \\
(n=1,093)\end{array}$} & No Change & Reference & \\
\hline & & Decreased by $\geq 1 \mathrm{~kg}$ & $1 \cdot 63(1 \cdot 30,2 \cdot 04)$ & $<0.001$ \\
\hline & & Increased by $\geq 1 \mathrm{~kg}$ & $1.40(1 \cdot 20,1 \cdot 63)$ & $<0.001$ \\
\hline & \multirow{3}{*}{$\begin{array}{l}\text { Normal weight } \\
(n=6,429)\end{array}$} & No Change & Reference & \\
\hline & & Decreased by $\geq 1 \mathrm{~kg}$ & $1 \cdot 62(1.45,1 \cdot 82)$ & $<0.001$ \\
\hline & & Increased by $\geq 1 \mathrm{~kg}$ & $1 \cdot 52(1.43,1 \cdot 62)$ & $<0.001$ \\
\hline & \multirow{3}{*}{$\begin{array}{l}\text { Overweight/Obese } \\
(n=2,876)\end{array}$} & No Change & Reference & \\
\hline & & Decreased by $\geq 1 \mathrm{~kg}$ & $1.48(1 \cdot 26,1 \cdot 73)$ & $<0.001$ \\
\hline & & Increased by $\geq 1 \mathrm{~kg}$ & $1 \cdot 61(1.46,1 \cdot 78)$ & $<0.001$ \\
\hline \multirow{5}{*}{\multicolumn{2}{|c|}{$\begin{array}{l}\text { Change in smoking } \\
(n=1,633)\end{array}$}} & No change & Reference & \\
\hline & & Increased a lot & $1 \cdot 54(1 \cdot 31,1 \cdot 82)$ & $<0.001$ \\
\hline & & Increased some & $1.42(1 \cdot 20,1 \cdot 68)$ & $<0.001$ \\
\hline & & Decreased some & $1 \cdot 04(0 \cdot 87,1 \cdot 23)$ & 0.679 \\
\hline & & Decreased lot & $0 \cdot 81(0 \cdot 65,1 \cdot 02)$ & 0.068 \\
\hline \multirow{5}{*}{\multicolumn{2}{|c|}{$\begin{array}{l}\text { Change in alcohol consumption } \\
(n=2,354)\end{array}$}} & No change & Reference & \\
\hline & & Increased a lot & $1.47(1 \cdot 24,1 \cdot 75)$ & $<0.001$ \\
\hline & & Increased some & $1 \cdot 67(1.45,1 \cdot 92)$ & $<0.001$ \\
\hline & & Decreased some & $1 \cdot 15(1 \cdot 01,1 \cdot 32)$ & 0.032 \\
\hline & & Decreased lot & $1 \cdot 12(0 \cdot 97,1 \cdot 28)$ & $0 \cdot 116$ \\
\hline \multirow{5}{*}{\multicolumn{2}{|c|}{$\begin{array}{l}\text { Change in physical activity } \\
(n=10,545)\end{array}$}} & No change & Reference & \\
\hline & & Increased a lot & $1 \cdot 53(1.42,1 \cdot 64)$ & $<0.001$ \\
\hline & & Increased a little & $1 \cdot 56(1.47,1 \cdot 66)$ & $<0.001$ \\
\hline & & Decreased a little & $1 \cdot 32(1 \cdot 24,1.41)$ & $<0.001$ \\
\hline & & Decreased lot & $1 \cdot 51(1.40,1 \cdot 62)$ & $<0.001$ \\
\hline
\end{tabular}

*Age, gender, marital status, educational attainment, ethnicity, residence, and number of chronic diseases were adjusted in all structural equation models. Separate models were fit for each outcome variable, respectively.

\section{Figures}




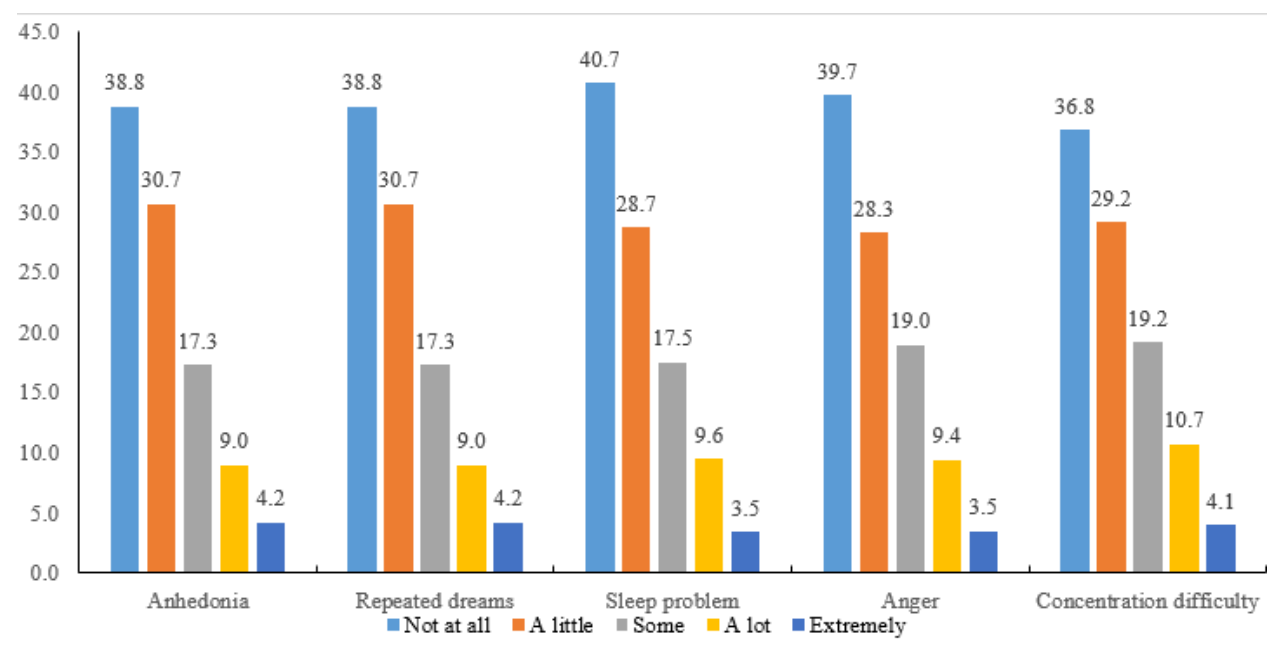

\section{Figure 1}

Percentage of five items related to mental distress of Chinese adults $(n=10,545)$ during the pandemic of COVID-19 a) Change in physical activity

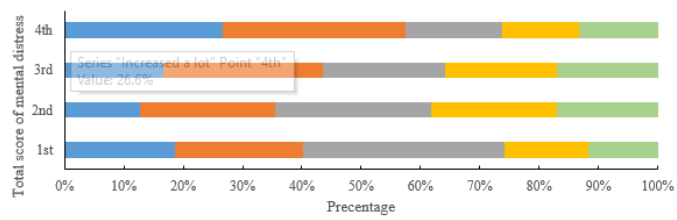

- Increased a lot $\mid$ Increased a little $\quad$ No change $\quad$ Decreased a little $\quad$ Decreased a lot

b) Change in smoking

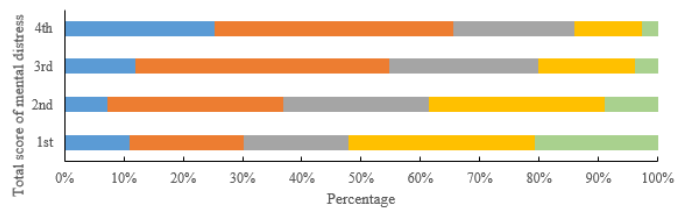

-High impact $=$ Some impact $\quad$ Average impact $=$ Minimal impact $\quad$ "No impact

c) Change in alcohol consumption

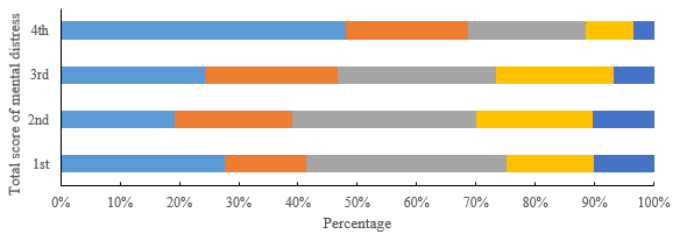

"Increase a lot "Increase some " No change " Decrease some "Decrease a lot

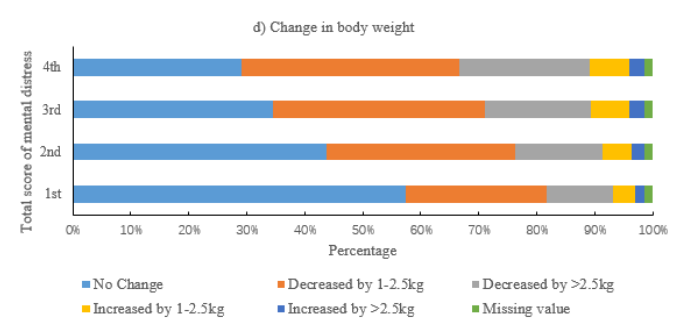

Figure 2

Distribution of changes in behavioral outcomes and body weight of Chinese adults $(n=10,545)$ by quartile of mental distress summary score

\section{Supplementary Files}

This is a list of supplementary files associated with this preprint. Click to download. 
- Mentalhealthofcovid19Supplemental.docx

Page 12/12 